PREPARED FOR THE U.S. DEPARTMENT OF ENERGY, UNDER CONTRACT DE-AC02-76CH03073

PPPL-3659

PPPL-3659

UC-70

Enhanced Mode Conversion of Thermally Emitted Electron

Bernstein Waves (EBW) to Extraordinary Mode

by

B. Jones, P.C. Efthimion, G. Taylor, T. Munsat, J.R. Wilson, J.C. Hosea,

R. Kaita, R. Majeski, R. Maingi, S. Shiraiwa, and J. Spaleta

January 2002

NM|

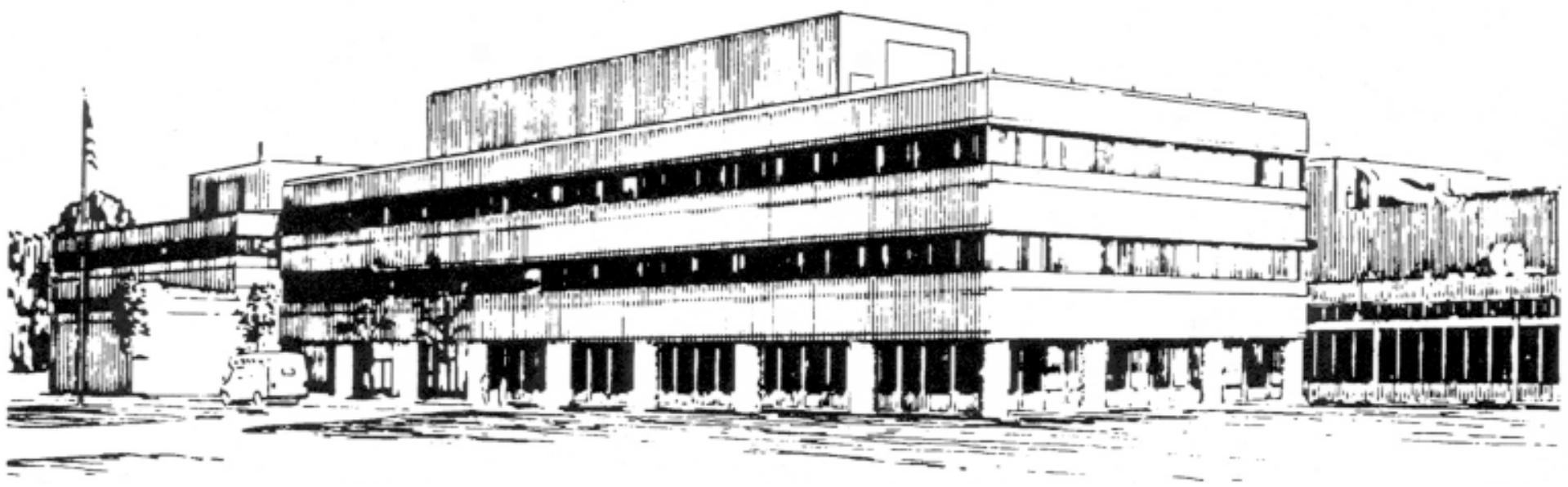

PRINCETON PLASMA PHYSICS LABORATORY PRINCETON UNIVERSITY, PRINCETON, NEW JERSEY 


\section{PPPL Reports Disclaimer}

This report was prepared as an account of work sponsored by an agency of the United States Government. Neither the United States Government nor any agency thereof, nor any of their employees, makes any warranty, express or implied, or assumes any legal liability or responsibility for the accuracy, completeness, or usefulness of any information, apparatus, product, or process disclosed, or represents that its use would not infringe privately owned rights. Reference herein to any specific commercial product, process, or service by trade name, trademark, manufacturer, or otherwise, does not necessarily constitute or imply its endorsement, recommendation, or favoring by the United States Government or any agency thereof. The views and opinions of authors expressed herein do not necessarily state or reflect those of the United States Government or any agency thereof.

\section{Availability}

This report is posted on the U.S. Department of Energy's Princeton Plasma Physics Laboratory Publications and Reports web site in Fiscal Year 2002. The home page for PPPL Reports and Publications is: http://www.pppl.gov/pub_report/

DOE and DOE Contractors can obtain copies of this report from:

U.S. Department of Energy

Office of Scientific and Technical Information

DOE Technical Information Services (DTIS)

P.O. Box 62

Oak Ridge, TN 37831

Telephone: (865) 576-8401

Fax: (865) 576-5728

Email: reports@adonis.osti.gov

This report is available to the general public from:

National Technical Information Service

U.S. Department of Commerce

5285 Port Royal Road

Springfield, VA 22161

Telephone: 1-800-553-6847 or

(703) 605-6000

Fax: (703) 321-8547

Internet: http://www.ntis.gov/ordering.htm 


\title{
Enhanced Mode Conversion of Thermally Emitted Electron Bernstein Waves (EBW) to Extraordinary Mode
}

\author{
B. Jones, ${ }^{*}$ P.C. Efthimion, ${ }^{*}$ G. Taylor, ${ }^{*}$ T. Munsat, J.R. Wilson, ${ }^{*}$ J.C. Hosea, \\ R. Kaita, ${ }^{*}$ R. Majeski, ${ }^{*}$ R. Maingi, S. Shiraiwa , J. Spaleta* \\ *Princteon Plasma Physics Laboratory, Princeton University, Princeton, New Jersey 08543 \\ Oak Ridge National Laboratory, Oak Ridge, Tennessee 37831 \\ Graduate School of Frontier Sciences, University of Tokyo, Tokyo 113-0033, Japan
}

In the CDX-U spherical torus, $\sim 100 \%$ conversion of thermal EBWs to X-mode has been observed by controlling the electron density scale length $\left(L_{n}\right)$ in the conversion region with a local limiter outside the last closed flux surface. The radiation temperature profile agrees with Thomson scattering electron temperature data. Results are consistent with theoretical calculations of conversion efficiency using measured $L_{n}$. By reciprocity of the conversion process, prospects for efficient coupling in EBW heating and current drive scenarios are strongly supported.

PACS numbers: 52.55.Fa, 52.35.Hr, 52.35.Mw, 52.70.Gw

In many high- $\beta$ magnetically confined plasmas, standard electron cyclotron emission (ECE) electron temperature $\left(T_{e}\right)$ profile diagnostics, as well as EC heating and current drive, cannot be employed since the electron plasma frequency is much larger than the electron cyclotron 
frequency $\left(f_{p e}>>f_{c e}\right)$. Fundamental and lower $f_{c e}$ harmonic electromagnetic waves are evanescent in the core of the plasma, and higher harmonics that are accessible do not meet the blackbody emission condition of optical thickness $\tau>2$. The electron Bernstein wave (EBW) has been proposed as an alternate method for measuring the $T_{e}$ profile in a high- $\beta$ plasma. $[1,2]$ Since the EBW is an electrostatic wave it can propagate above the critical density in a magnetized plasma, and is strongly absorbed at the $f_{c e}$ harmonics, with $\tau \approx 300$ in CDX-U. [2,3,4] The EBW can mode-convert to either an O- or X-mode electromagnetic wave at the upper hybrid resonance (UHR) layer. The resulting electromagnetic waves emitted can be measured with an antenna and radiometer as in the standard ECE technique.

Conversion between EBW and O-mode waves via the slow X-mode (B-X-O process) occurs at oblique angles in a narrow range of $n_{/ /}$whose optimal value is determined by $f_{c e} / f$ and whose width is generally determined by the electron density scale length $\left(L_{n}\right)$ in the conversion region. [5] This process has been extensively studied in both emission and heating experiments on the W7-AS stellarator, with results in good agreement with theory. $[1,6]$

EBW conversion to X-mode (B-X process) occurs for $n_{/ /} \approx 0$ with a mode conversion efficiency (C) sensitively dependent on $L_{n}$ in the conversion region at the UHR. A 1D slab model results in the analytic theory for $n_{/ /}=0$ presented in [7]. The full expression for mode conversion efficiency is

$$
C=C_{\max } \cos ^{2}(\phi / 2+\theta)
$$

where $\cos ^{2}(\phi / 2+\theta)$ is a factor relating to the phasing of the waves in the mode conversion region with $\theta=\arg \Gamma(-i \eta / 2)$, and $\phi$ evaluated in the manner of [8] for the case of the high-field cutoff close to resonance. The maximum mode conversion efficiency $\left(C_{\max }\right)$ is given by

$$
C_{\max }=4 \mathrm{e}^{-\pi \eta}\left(1-\mathrm{e}^{-\pi \eta}\right)
$$


When the magnetic scale length in the mode conversion region $L_{B}>>L_{n}$ as in CDX-U,

$$
\eta \approx\left(2 \pi f_{c e} L_{n} /(c \alpha)\right)\left(\left(1+\alpha^{2}\right)^{1 / 2}-1\right)^{1 / 2}
$$

where $\alpha=f_{p e} / f_{c e}$ evaluated at the UHR layer. This conversion is expected to be less sensitively dependent on $n_{/ /}$, and is the process we have studied in CDX-U. It is also being studied on the MST reversed-field pinch. [9]

Obtaining $C \sim 100 \%$, or equivalently radiation temperature $T_{\text {rad }} \sim T_{e}$, requires $L_{n} \approx 0.5 \mathrm{~cm}$ in CDX-U. Optimizing $C$ is also desirable so that power can be effectively coupled to the plasma for EBW heating and current drive. Studying EBW emission evaluates the same mode conversion physics that affects the inverse processes of heating and current drive [10], so this research tests the viability of proposed X-mode EBW current drive schemes. [11,12]

Further distinguishing emission measurements on CDX-U from those performed on other machines is that in an ST, the mode conversion for lower harmonics typically occurs outside the last closed flux surface (LCFS). $L_{n}$ can be diagnosed by Langmuir probes and modified by material limiters in this region.

Two independently calibrated, fast frequency scanning, heterodyne radiometers measure fundamental (4-8 GHz) and second harmonic (8-12 GHz) EBW emission every $20 \mu \mathrm{s}$. [13] Localization of the EBW emission source to the $f_{c e}$ resonant surfaces has been verified by observing the response of the $T_{\text {rad }}$ profile to cooling gas puffs at the plasma edge. $[1,14]$ This justifies a comparison between the measured $T_{r a d}$ and Thomson scattering $T_{e}$ profiles in order to infer a value of $C$. In previous experiments with an antenna outside a vacuum window on CDXU, $C \sim 10 \%$ was observed. [12] Similar observations have been made on NSTX, resulting in good agreement with theoretical $C$ calculated using $L_{n}=1.5 \mathrm{~cm}$, as measured by Thomson scattering. 
[15] However, even with the steep edge density profile provided by an NSTX H-mode, a maximum mode conversion efficiency of only $15 \%$ was observed.

Rather than relying on the density profile naturally provided by the plasma, it is necessary to create a shorter $L_{n}$ at the UHR layer outside the LCFS in order to reach $C \sim 100 \%$. To meet this goal, an in-vacuum antenna along with a movable local limiter has been installed in CDX-U, shown in Fig. 1. The quad-ridged horn antenna points perpendicular to the LCFS $\left(n_{/ /} \approx 0\right)$ on the outboard midplane, oriented with the edge field line pitch so as to measure predominantly Xmode emission with one set of ridges and O-mode with the other. X-mode $T_{\text {rad }} 2-3$ times greater than O-mode $T_{r a d}$ is measured, consistent with the lower sensitivity of the O-mode antenna to rays with $n_{/ /} \neq 0$. The local limiter shortens $L_{n}$ in the scrape-off layer (SOL) where the B-X mode conversion occurs for $f_{c e}$ and $2 f_{c e}$, thus optimizing $C$ for $\sim 100 \%$ conversion. As the conversion occurs outside the LCFS, the local limiter only modifies the density profile in the SOL immediately in front of the antenna and is not the primary limiter for the plasma.

Also shown in Fig. 1, an array of Langmuir probes adjacent to the antenna measures the density profile in the mode conversion region so that the observed emission can be compared to $C$ calculated using $L_{n}$ measurements. These $5 \mathrm{~mm}$ long cylindrical probes can be swept in voltage to measure $T_{e}$ or biased negatively to measure ion saturation current $\left(I_{\text {sat }}\right)$ from which electron density $\left(n_{e}\right)$ can be calculated.

Figure 2 (a) shows the significant steepening of $L_{n}$ outside the LCFS due to the local limiter. For each point, data were averaged for approximately five shots with similar plasma parameters. $I_{\text {sat }}$ was averaged over $0.1 \mathrm{~ms}$ during each shot in order to smooth out fluctuations. The profile naturally occurring in the SOL with $L_{n}=3-6 \mathrm{~cm}$ (diamonds, dashed line) was measured by scanning the entire assembly, using the furthest inboard tip which is unperturbed by the local 
limiter. With the local limiter located near the LCFS and measuring $n_{e}$ with the probe tips outboard of the limiter (triangles), an average density scale length $L_{n}=0.66 \pm 0.07 \mathrm{~cm}$ was measured (solid line is a best fit to three points). As will be discussed, this value is consistent with $\sim 100 \%$ B-X conversion efficiency.

Using these density profiles, the UHR frequency $f_{U H}=\left(f_{p e}{ }^{2}+f_{c e}{ }^{2}\right)^{1 / 2}$ is calculated as a function of major radius in Fig. 2 (b). $f_{c e}$ is calculated using $|\mathrm{B}|$ from the equilibrium code JSOLVER constrained to the measured toroidal plasma current (60 kA). [16] Since $B_{p}<<B_{t}$ in CDX-U, JSOLVER is expected to provide a reasonable estimate of $|\mathrm{B}|$. An EBW of a given frequency mode-converts when the outgoing wave reaches the radial position at which $f=f_{U H} . \quad f_{U H}$ calculated using the natural SOL $n_{e}$ profile (dashed line) illustrates that in CDX-U, the fundamental and second harmonic EBW mode conversion naturally occurs in the SOL, near the vessel wall at $R=70 \mathrm{~cm}$ in the case of the $4-8 \mathrm{GHz}$ fundamental emission. With the local limiter present (solid line), the mode conversion for $4-12 \mathrm{GHz}$ occurs in a few-centimeter-wide UHR layer between the limiter and antenna position where $L_{n}$ is shortened.

The effect of the local limiter on the EBW emission is seen in Fig. 3. With the antenna and local limiter retracted near the vessel wall so that the mode conversion occurs in a region with long $L_{n}$, the fundamental emission is observed at a low level (triangles). With the local limiter near the LCFS so that the mode conversion occurs in a region of short $L_{n}$, we see the emission increase by an order of magnitude (diamonds, solid line). We also plot the second harmonic $T_{\text {rad }}$ (diamonds, dashed line), and note that there is favorable agreement with Thomson scattering $T_{e}$ data (squares) for both fundamental and second harmonic mode-converted EBW emission with $L_{n}$ shortened by the local limiter. The hollow temperature profile is typical, and is expected as CDX-U is a short-pulse machine with a plasma duration of $\sim 15 \mathrm{~ms}$. Only a $30 \%$ reduction in 
second harmonic $T_{\text {rad }}$ is seen without the local limiter, likely due to the natural steepening of $L_{n}$ near the LCFS seen in Fig. 2.

The EBW $T_{\text {rad }}$ points were mapped from radiometer frequency to $R$, with error bars reflecting the frequency resolution of the radiometers shown on selected points. $15 \% T_{\text {rad }}$ error bars are due to systematic error in the absolute calibration, performed using Dicke-switching of a blackbody source. [17] Data points obscured by cyclotron harmonic overlap or for which the mode conversion region is perturbed by the presence of the antenna are not shown.

The Thomson scattering measurements are taken along a vertical axis $(z)$ at a fixed beam radial position. Plotted in Fig. 3 is the average of two data sets for similar CDX-U discharges measured at the start of the time window in Fig. 4. $T_{e}$ for each set results from a fit to scattered spectra integrated over $16-48$ shots to resolve low photon statistics. Mapping from $z$ to $R$ is performed using canonical CDX-U flux surface shapes. Error bars in $R$ are calculated by perturbing the location of the magnetic axis and the plasma elongation. The mapping of the points to outboard radial positions far from the Thomson laser location is especially sensitive to the shape of the flux surfaces, resulting in larger error bars in $R$. Points closer to the center of the plasma are not available because the laser beam does not pass through the magnetic axis.

Large fluctuations in the emission signal are observed, which we interpret as being due to variation in $L_{n}$ resulting from density fluctuations at the local limiter. These fluctuations can be seen in the time evolution of $T_{\text {rad }}$ and $I_{\text {sat }}$ shown in Fig. 4. The $T_{\text {rad }}$ profiles shown in Fig. 3 represent single radiometer sweeps selected at the peak of fluctuating emission within the analysis time window. Vertical arrowed lines show the peak-to-peak fluctuation at $6 \mathrm{GHz}$ and $10 \mathrm{GHz}$. Note that the fluctuation is greater at $6 \mathrm{GHz}$, extending down to about $10 \%$ of the peak signal, while the $10 \mathrm{GHz}$ fluctuation drops to only about $40 \%$ of the maximum $T_{e}$. 
The $n_{e}$ profile data from the probes and the EBW emission measurements can test the theory of B-X mode conversion presented in [7]. Fig. 5 (c) shows theoretical mode conversion efficiency $C$ calculated from equation (1) as a function of $L_{n}$ at both 6 and $10 \mathrm{GHz}$ (fundamental and second harmonic emission frequencies). The average $L_{n}$ measured behind the local limiter is shown (dashed vertical line), with the shaded region representing the error bars. It is seen that $C \sim 100 \%$ is theoretically attainable with the short $L_{n}$ produced by the local limiter, consistent with the comparison between $T_{r a d}$ and Thomson $T_{e}$ profiles. Interpreting the fluctuating emission observed as being due to fluctuations carrying $L_{n}$ out to near $2 \mathrm{~cm}$ (dotted line), we see that the theoretical $C$ drops to $10 \%$ for the $6 \mathrm{GHz}$ case and $40 \%$ for $10 \mathrm{GHz}$. This is consistent with the observed fluctuation in the emission signal, as shown in Fig. 3, and with the 0.4 and $3.4 \mathrm{~cm}$ worst-case limits on $L_{n}$ obtained by considering the ranges of fluctuating $n_{e}$ measured at the probe locations spanning the conversion layer. Note that had we neglected the phase factor and calculated only $C_{\max }$ versus $L_{n}$ (Fig. 5 (a)), we would not have predicted the differing levels of $T_{\text {rad }}$ fluctuation observed. It is the frequency dependence in $\cos ^{2}(\phi / 2+\theta)$ near $L_{n} \sim 2 \mathrm{~cm}$ (Fig. 5 (b)) that leads to this difference in $C$ at 6 and $10 \mathrm{GHz}$.

Further evidence that fluctuating $L_{n}$ is playing a role in modifying $C$, leading to fluctuating emission, is seen by comparing the $T_{\text {rad }}$ and probe $I_{\text {sat }}$ time evolution. For several probe tip positions, the cross-correlation between these signals was calculated in a time window approximately $1 \mathrm{~ms}$ wide. $70 \%$ anti-correlation was observed for the probe located $0.6 \mathrm{~cm}$ behind the local limiter and emission at $5.5 \mathrm{GHz}$, which mode-converts near the probe location. The emission peaked when the density behind the limiter dropped, consistent with $L_{n}$ shortening. Correlation was not seen for probes $2 \mathrm{~cm}$ on either side of this location. 
$100 \%$ B-X mode conversion efficiency has been observed in CDX-U by controlling $L_{n}$ at the UHR layer, allowing direct measurement of the $T_{e}$ profile from mode-converted EBW emission. The measured $T_{e}$ profile was similar to that measured by Thomson scattering. $\mathrm{C} \sim 100 \%$ and measured $L_{n}$ at the UHR are consistent with the theory of [7]. The $\cos ^{2}(\phi / 2+\theta)$ phase factor in this theory has been found to be important, and explains the frequency dependence of the observed $T_{r a d}$ fluctuations. Since the mode conversion occurs in the SOL for an ST, $L_{n}$ can be controlled and optimized with a local limiter that does not perturb the plasma. Similarly, reciprocity of the mode conversion process is a strong justification for using a local limiter with an X-mode electromagnetic heating or current drive antenna to achieve efficient coupling to the EBW branch.

The authors would like to thank the CDX-U technical staff and T. Kramer for their contributions. This work was supported by DOE Contract No. DE-AC02-76-CHO-3073 as part of the Innovations in Magnetic Fusion Energy Diagnostic Systems program. 
[1] H. P. Laqua et al., Phys. Rev. Lett. 81, 2060 (1998).

[2] P. C. Efthimion et al., Rev. Sci. Instrum. 70, 1018 (1999).

[3] J. Hosea, V. Arunasalam, and R. Cano, Phys. Rev. Lett. 39, 408 (1977).

[4] T. Jones, Ph.D. Thesis, Princeton U. (1995).

[5] J. Preinhaelter and V. Kopecky, J. Plasma Phys. 10, 1 (1973).

[6] H. P. Laqua et al., Phys. Rev. Lett. 78, 18 (1997).

[7] A. K. Ram and S. D. Schultz, Phys. Plasmas 7, 4084 (2000).

[8] A. K. Ram et al., Phys. Plasmas 3, 1976 (1996).

[9] P. K. Chattopadhyay et al., AIP Conference Proceedings 595, 346 (2001).

[10] A. K. Ram, A. Bers, and C. N. Lashmore-Davies, Phys. Plasmas 9, 409 (2002).

[11] C. B. Forest et al., Phys. Plasmas 7, 1352 (2000).

[12] G. Taylor et al., AIP Conference Proceedings 595, 282 (2001).

[13] G. Taylor et al., Rev. Sci. Instrum. 72, 285 (2001).

[14] T. Munsat et al., Phys. Plasmas 9, 480 (2002).

[15] G. Taylor et al., Phys. Plasmas 9, 167 (2002).

[16] J. Delucia et al., J. Comput. Phys. 37, 183 (1980).

[17] R. H. Dicke, Rev. Sci. Instrum. 17, 268 (1946). 
FIG. 1. The CDX-U EBW diagnostic combines a quad-ridged horn antenna to measure emission, a movable local limiter (half shown) to modify $L_{n}$ in front of the antenna to optimize mode conversion, and a Langmuir probe array to measure $L_{n}$.

FIG. 2. (a) The $L_{n}=3-6 \mathrm{~cm}$ electron density profile naturally occurring in the SOL (diamonds, dashed line) and the $L_{n}=0.66-0.07 \mathrm{~cm}$ profile created by the local limiter (triangles, solid line). (b) The corresponding UHR frequency profiles, determining the mode conversion location for a wave of frequency $f=f_{U H}$. The local limiter creates a narrow mode conversion layer in front of the antenna for the fundamental and second harmonic EBW frequency ranges (shown shaded).

FIG. 3. The radiation temperature without the local limiter (triangles). With the local limiter, the peak fundamental emission (diamonds, solid line) and second harmonic emission (diamonds, dashed line) together map out the $T_{e}$ profile and are consistent with $T_{e}$ measured by Thomson scattering (squares). The emission fluctuation levels at 6 and $10 \mathrm{GHz}$ are indicated by vertical arrowed lines.

FIG. 4. Time evolution of a typical CDX-U discharge. (a) Toroidal plasma current, (b) lineaveraged density $(R=35 \mathrm{~cm}),(\mathrm{c})$ ion saturation current from Langmuir probes showing edge $n_{e}$ fluctuation (local limiter at $R=56.6 \mathrm{~cm}$, data from two separate shots), and (d) EBW $T_{\text {rad }}$ at 10 $\mathrm{GHz}$, showing multiple peaks resulting from gas puff modulation and fluctuation resulting from changing $L_{n}$. Analysis was performed in the shaded time window. 
FIG. 5. (a) The maximum mode conversion efficiency $C_{\max }$ for $6 \mathrm{GHz}$ (solid) and $10 \mathrm{GHz}$ (dashed) emission as a function of $L_{n}$ just outside the CDX-U LCFS, (b) the $\cos ^{2}(\phi / 2+\theta)$ phase factor, and (c) the theoretical mode conversion efficiency $C=C_{\max } \cos ^{2}(\phi / 2+\theta)$. 


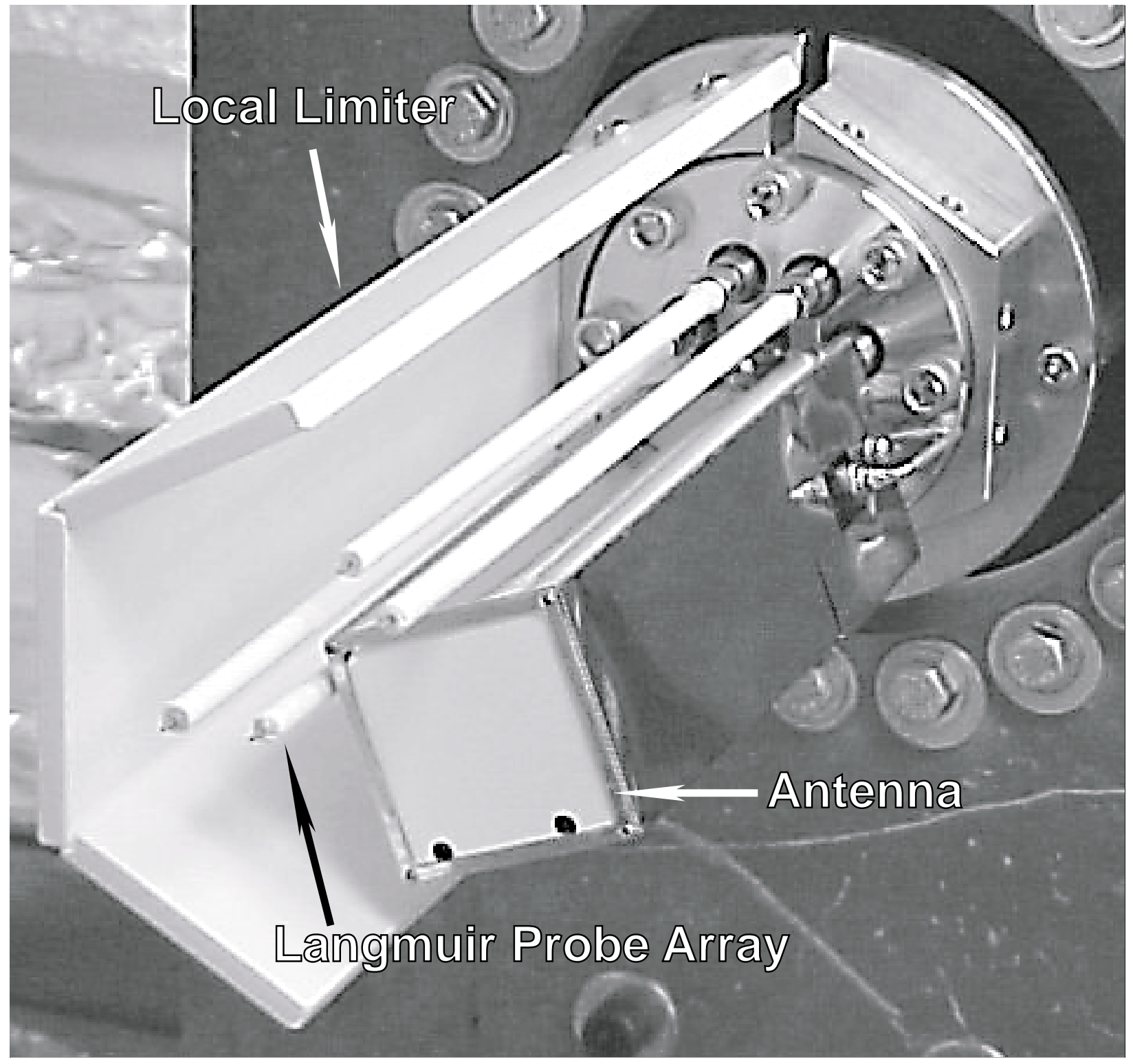

FIGURE 1, B. Jones, Phys. Rev. Lett. 


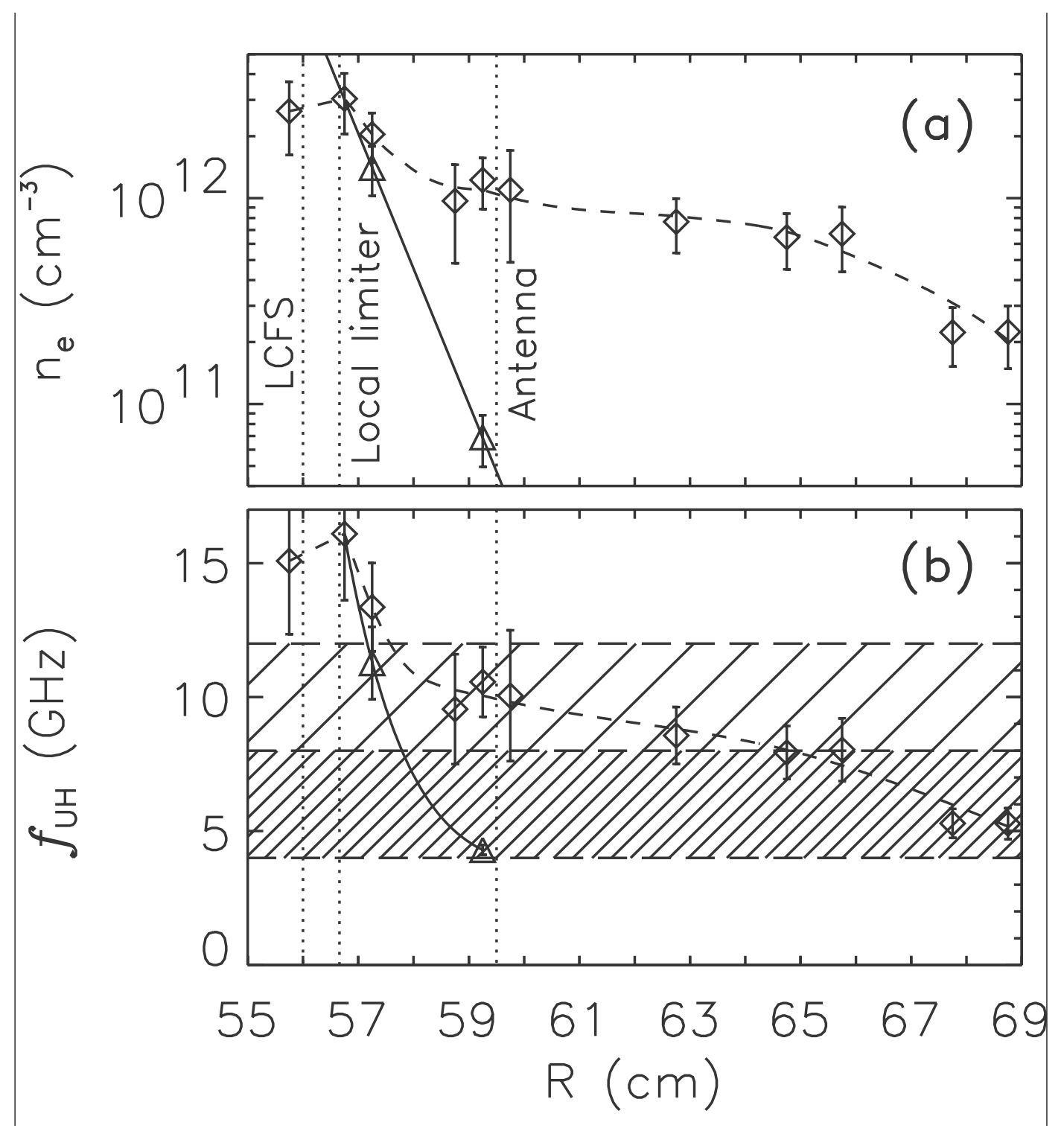

FIGURE 2, B. Jones, Phys. Rev. Lett. 


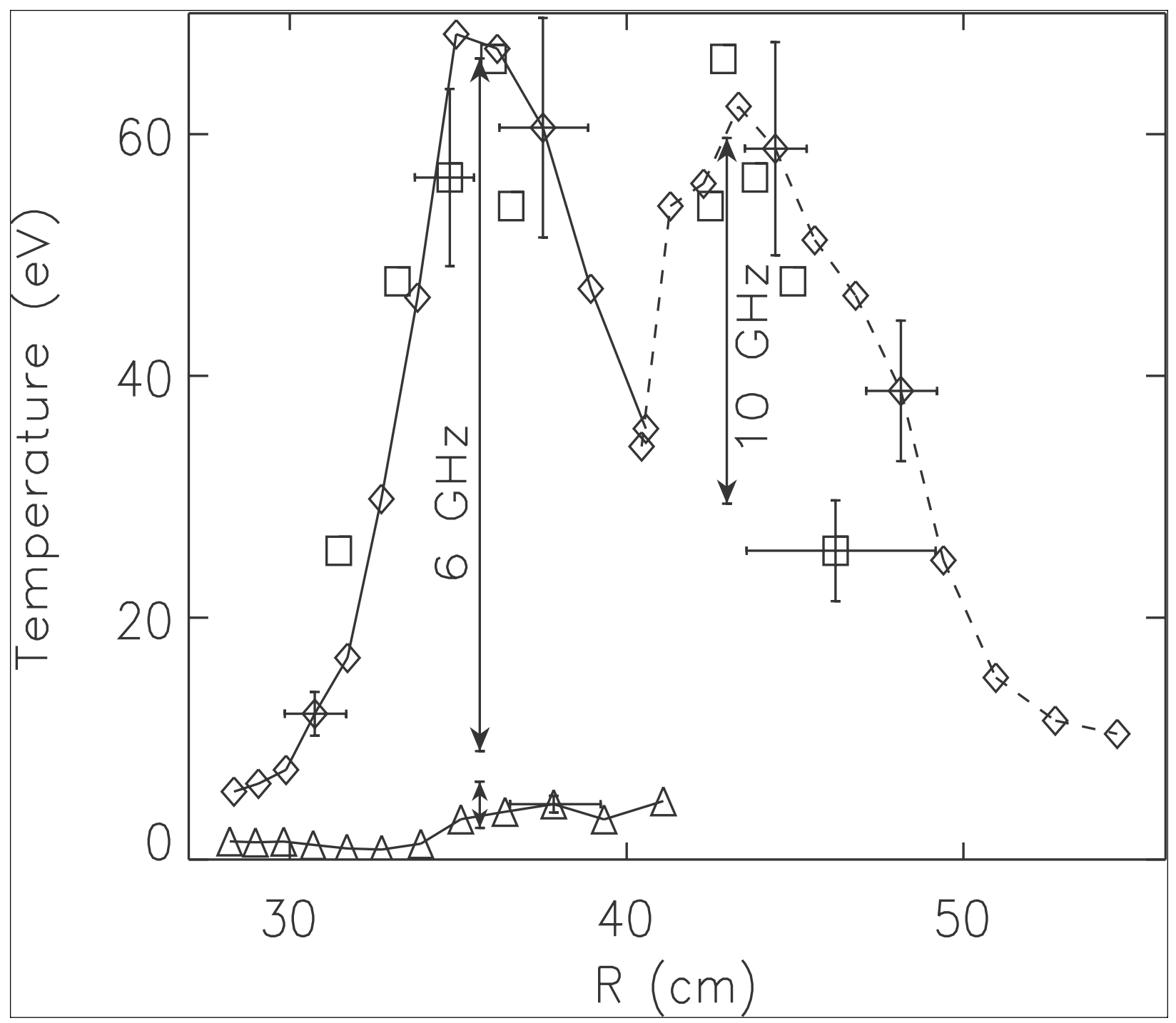

FIGURE 3, B. Jones, Phys. Rev. Lett. 


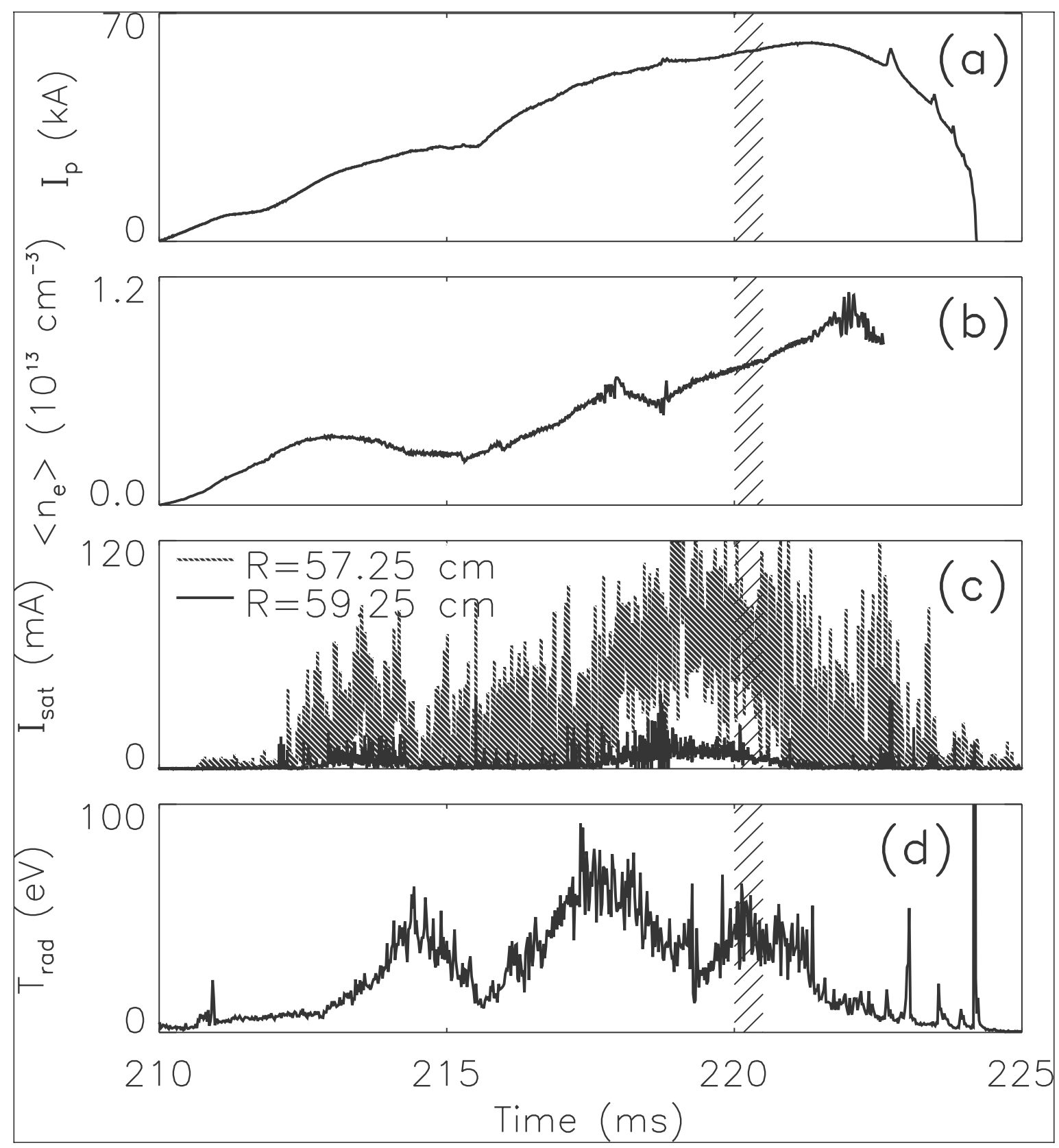

FIGURE 4, B. Jones, Phys. Rev. Lett. 


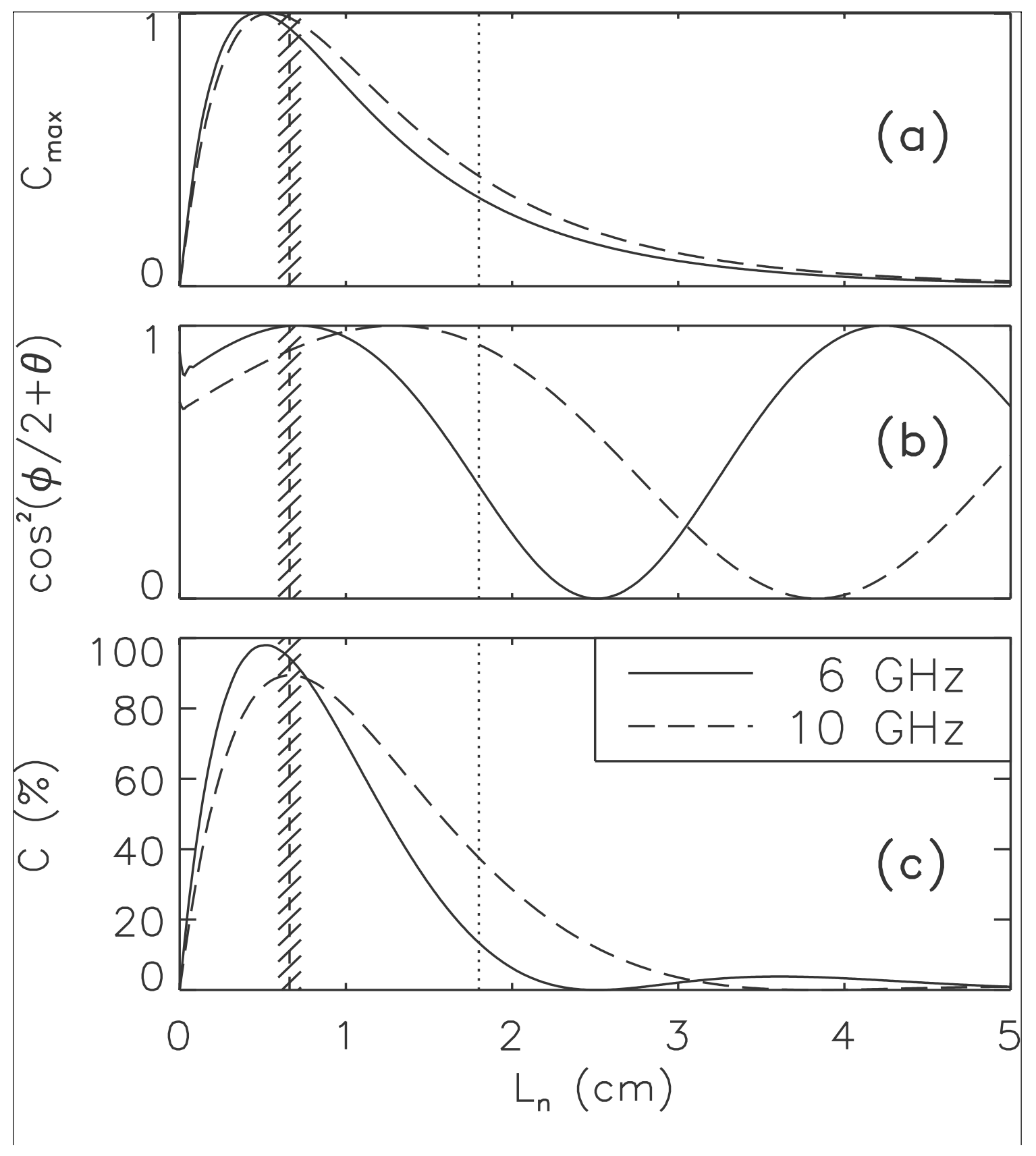

FIGURE 5, B. Jones, Phys. Rev. Lett. 


\section{External Distribution}

Plasma Research Laboratory, Australian National University, Australia

Professor I.R. J ones, Flinders University, Australia

Professor J oão Canalle, Instituto de Fisica DEQ/IF - UERJ , Brazil

Mr. Gerson O. Ludwig, Instituto Nacional de Pesquisas, Brazil

Dr. P.H. Sakanaka, Instituto Fisica, Brazil

The Librarian, Culham Laboratory, England

Library, R61, Rutherford Appleton Laboratory, England

Mrs. S.A. Hutchinson, JET Library, England

Professor M.N. Bussac, Ecole Polytechnique, France

Librarian, Max-Planck-Institut für Plasmaphysik, Germany

J olan Moldvai, Reports Library, MTA KFKI-ATKI, Hungary

Dr. P. Kaw, Institute for Plasma Research, India

Ms. P.J . Pathak, Librarian, Insitute for Plasma Research, India

Ms. Clelia De Palo, Associazione EURATOM-ENEA, I taly

Dr. G. Grosso, Instituto di Fisica del Plasma, Italy

Librarian, Naka Fusion Research Establishment, J AERI, J apan

Library, Plasma Physics Laboratory, Kyoto University, J apan

Research Information Center, National Institute for Fusion Science, J apan

Dr. O. Mitarai, Kyushu Tokai University, J apan

Library, Academia Sinica, Institute of Plasma Physics, People's Republic of China

Shih-Tung Tsai, Institute of Physics, Chinese Academy of Sciences, People's Republic of China

Dr. S. Mirnov, TRINITI, Troitsk, Russian Federation, Russia

Dr. V.S. Strelkov, Kurchatov Institute, Russian Federation, Russia

Professor Peter Lukac, Katedra Fyziky Plazmy MFF UK, Mlynska dolina F-2, Komenskeho Univerzita, SK-842 15 Bratislava, Slovakia

Dr. G.S. Lee, Korea Basic Science Institute, South Korea

Mr. Dennis Bruggink, Fusion Library, University of Wisconsin, USA

Institute for Plasma Research, University of Maryland, USA

Librarian, Fusion Energy Division, Oak Ridge National Laboratory, USA

Librarian, Institute of Fusion Studies, University of Texas, USA

Librarian, Magnetic Fusion Program, Lawrence Livermore National Laboratory, USA

Library, General Atomics, USA

Plasma Physics Group, Fusion Energy Research Program, University of California at San Diego, USA

Plasma Physics Library, Columbia University, USA

Alkesh Punjabi, Center for Fusion Research and Training, Hampton University, USA

Dr. W.M. Stacey, Fusion Research Center, Georgia Institute of Technology, USA

Dr. J ohn Willis, U.S. Department of Energy, Office of Fusion Energy Sciences, USA

Mr. Paul H. Wright, Indianapolis, Indiana, USA 
The Princeton Plasma Physics Laboratory is operated by Princeton University under contract with the U.S. Department of Energy.

\author{
Information Services \\ Princeton Plasma Physics Laboratory \\ P.O. Box 451 \\ Princeton, NJ 08543
}

Phone: 609-243-2750

Fax: 609-243-2751

e-mail: pppl_info@pppl.gov

Internet Address: http://www.pppl.gov 